\title{
Aboriginal contributions to the evaluation of housing (and to postcolonial theory)
}

\begin{tabular}{c|c}
\hline Michael Christie & Matthew Campbell \\
Northern Institute & Tangentyere Council \\
Charles Darwin University & matthew.campbell@tangentyere.org.au \\
michael.christie@cdu.edu.au & \\
\hline
\end{tabular}

Keywords: Aboriginal evaluation, Indigenous evaluation, housing reference groups, ground up evaluation, evaluation policy impact, double participation, cross-cultural evaluation

\begin{abstract}
Housing Reference Groups (HRGs) began to be established in remote Northern Territory (NT) Aboriginal communities in 2009 when the Northern Territory Government compulsorily acquired remote Aboriginal housing and closed down 75 Aboriginal Housing associations. In this highly contested context, we were invited to undertake an evaluation of the HRGs. Through both open discussion and semi-structured interviews, we learnt from the Aboriginal people we worked with to see a much wider, more structural understanding of housing and its governance. This in turn led us to reflect upon Aboriginal contributions to the theory and practice of evaluation, and their various relations to received theories such as social justice, pragmatist philosophy and ethics, and Frierian conscientization. This collaborative ground-up evaluation process contributed to our own ongoing practices of evaluation, and possibly to some slight but reverberating changes in government policy and practice.
\end{abstract}

\section{Introduction}

Remote Housing NT is a division of the NT Department of Housing which was established to manage the delivery and improvement of Aboriginal public housing in the Northern Territory. It is a system through which the NT and Australian governments are implementing their National Partnership Agreement on Remote Indigenous Housing (NPARIH; 2009). The introduction of Remote Housing NT saw all Aboriginal housing previously managed under Aboriginal Housing Associations converted into public housing. This entailed 
the government acquisition through compulsory leasing of Aboriginal land for public housing. Two construction company consortia known as Alliances were engaged to deliver the Strategic Indigenous Housing and Infrastructure Program (SIHIP), an element of NPARIH (2009) in which houses will be built, rebuilt or refurbished. Housing Reference Groups (HRGs) were set up in 73 communities, a number of Town Camps and other 'living areas' 'to work with government and ensure local communities had input into decisions about housing in their community'. HRGs were to advise on, but not to allocate, housing. Allocation and repair and maintenance decisions are ultimately to be made by the Department.

The 'Consultation for Better Housing' project was an element of a much larger Australian Research Council project called 'More Than a Roof Overhead' (MTRO). MTRO sought to take a broad, whole-of-system and interdisciplinary approach in research on the delivery and management of remote Indigenous housing where the key challenge is to design, build and manage housing as an integrated and sustainable system. Our subproject was to look at the consultation and engagement mechanisms that existed in the NT and the extent to which they were facilitating dialogue between housing users and administrators.

We write this paper as two academics who have been involved in grounded research and evaluation work in Aboriginal contexts for 40 and 20 years respectively. In this project we were determined from the beginning that this would not be a conventional evaluation, where we would go in with the questions already prepared, and to which we would write down the responses. We had worked together before on a range of projects around Indigenous community engagement which had led us to understand the research process (and the evaluation that emerges from it) as a work practice in which participants collectively and iteratively define the issue being researched while undertaking action to produce change (Christie, 2013a). As such we had moved from understanding research as a process of 'finding things out' to a social process in which the world changes through our acts. In this sense we understand knowledge as action and performative, rather than representational. This orientation led us to fundamentally rethink what it means to be a researcher, making a decisive move from being a 'judging observer' to being a (albeit privileged) 'participant in collective action' (Addelson, 1993). Taking the position of a 'participant in collective action' also entails thinking about methodology, as we must work to ensure our research is generative producing tangible change in the world. We will return to these points later in the paper.

This paper first outlines the methods we used, and then summarises the findings, recommendations and conclusions. This is followed by a section where we reflect quite specifically on the contributions of Aboriginal people to our thinking about practices of evaluation. We also make some comments on how these principles of evaluation are echoed by and extend theoretical positions coming out of the academic (enlightenment) tradition. We conclude with a short discussion of some surprising insights and outcomes of the project. 


\section{Method}

There was no escaping the fact that ours was not an arms-length evaluation. We had been invited to undertake the evaluation because our research showed a history of theoretical and practical engagement with Aboriginal people that was seen by government as being both just and productive. Everyone, right up to senior bureaucrats, accepted that Aboriginal people in remote places had been disempowered since the NT Emergency Response. Houses they used to own and manage collectively, were not, in their eyes, public housing. Yet that was exactly what they had become, according to the government. So often we heard of the shock of Aboriginal residents being told by government workers: 'This is not your house any more'. Everyone therefore had an interest in the HRGs being effective, even if only as a way of addressing the range of difficult conversations in remote communities that had emerged around housing as a result of the takeover. We were welcomed by the Aboriginal residents and HRG members (and the public servants) because they could see we were there to listen and to help.

In the first phase of the research, a group of Aboriginal elders were brought together to a 'workshop' to discuss the housing in their communities and homeland centres, past present and future, and their views and recommendations for the communitybased HRGs. They were paid for their work. In the second phase, we conducted semi-structured interviews with senior bureaucrats in the Department of Housing, with 'street-level bureaucrats' (Lipsky, 1980) working to organise housing and HRGs in remote communities, and Aboriginal members of HRGs and senior local authorities. The senior managers of the Department of Housing (which had contributed funding to the research) were keen to see the interviews in the second phase focus upon specific areas of interest. We negotiated with them around these areas, and together we came up with what we came to know as the 'focus area' list. This list included: evaluate the size and representatively of the HRGs, their selection and review processes; their Terms of Reference, roles and governance arrangements, payment and time commitment, and frequency of meetings; the future of the HRGs after SIHIP; the relationship of the HRG to other bodies like the shire 'Local Boards' etc; and the government's communication and feedback structures and processes. We were told not to open the question of sitting fees for HRG members, as remuneration was 'out of the question'. Although the focus area list appeared like a set of questions, in practice we used it as a starting point for discussions and each interview unfolded differently.

We began by talking with senior NT Government bureaucrats within the Department of Housing. The interviews were semi-structured, using the focus area list as a basis. The interviews were taped and transcribed; the transcriptions and a summary we made from them were returned to the interviewee for comment and changes if required. At the conclusion of each interview we asked if there were other people we should seek to speak to about the same set of questions. In this way we were led to others within the Department dealing with remote housing at all levels, from those responsible for management of housing or for policy development and implementation, to those 
engaged in day to day, face to face interactions with Aboriginal residents.

In a parallel process we talked to Aboriginal members of HRGs in both remote communities and Alice Springs Town Camps. Again the same process applied, of recorded semi-structured interviews conducted using the focus areas list. We paid HRG participants for their time if they were not otherwise in paid employment while doing the interview. We consider that people in such interviews are providing us with access to their knowledge, which is valuable and which needs to be recognised in the form of payment. Our experience shows us that Aboriginal people view their knowledge differently from non-Aboriginal people, and that acting in good faith requires recognising these perspectives. Our experience also shows us that Aboriginal people recognise and appreciate this.

Our interviews were conducted either as one-on-one interviews or interviews with small groups. The particular configuration depended on our relationship with the person being interviewed and what made them feel comfortable. We conducted interviews with bureaucrats in their offices, and with Aboriginal people in our offices, over the phone and in community centres. In some situations we knew the Aboriginal people we were interviewing through previous work; they were comfortable talking to us in ways that they might not use with people they did not know.

Once comfortably ensconced wherever we were, we were told stories. These stories ranged from the old days and the ancestral metaphors for housing, to the way housing manages people and the difficulties experienced by bureaucrats in finding a quorum for an HRG meeting, from dissatisfaction about communication practices to stories about how the change in housing management has created myriad problems that are beyond the scope of tenancy agreements and repairs and maintenance regimes. The diversity of these stories indicated to us that housing, and the HRGs as a consultation tool, could not be talked about simply or instrumentally, and recommendations to improve their functioning would address only a small part of the problem. Indeed each person we interviewed talked about quite different things. Yet it was apparent that their perspectives were all connected, and we hoped that through our generative analysis approach we might be able to make some practical contributions that would assist people wherever they found themselves within the system.

Our approach was founded on the assumption that our research process had the potential to make connections between the stories of the participants regardless of where they sat within the housing system. We theorised that our process would assist participants to see things that previously they could not see, and hopefully begin to make changes in their practices based upon seeing things in new ways. We made a transcription of everyone's interview which we sent back to them accompanied by a summary in which we identified what we thought were the major points to emerge. We invited each participant to review this material and get back to us with any changes, adding things, removing things or clarifying whether our summaries made sense. We asked Aboriginal participants if they would like us to revisit them with the view to making any required changes to their interviews.

We also looked at these summaries collectively and tentatively put together another 
story (what we called the mega-summary) that sought to draw together the disparate range of issues, practices and concerns that emanated from the field. We then distributed the overall summary. Our hope was that this would elicit feedback and interest in particular issues or areas that we could then focus on with the participants. Our rationale at this point was not to try to develop a coherent story ourselves, but to draw the other participants in to the knowledge making process.

However, interestingly and frustratingly only one person got back to us with feedback. In hindsight, it is possible that the approach we took was not the most appropriate way to elicit feedback, particularly from the Aboriginal participants whose grasp of English may not have been great or who were uncomfortable coming back to us with concerns. However, the lack of response was consistent from all (bar one) of the people interviewed. Undeterred, we continued interviewing more people using the same process. In the end we interviewed 15 people (bureaucrats and Aboriginal HRG members), and analysed and summarised over 100,000 words of transcription, from which we developed a draft report. This again was distributed with invitations for feedback and comment, with a particular focus on the findings and our proposed recommendations. Again we did not receive any feedback. We also distributed the report to other researchers within the MTRO project, who thought that our approach, findings and recommendations were interesting and useful for the purposes of the project overall.

\section{Findings}

The final report for government, community, and the public was in the form of a '1-325': one page of 'main messages', three pages of executive summary, and a full report. This was to make the report accessible to a range of people, some of whom would be interested in the detail, others only in the 'take home' messages. The bulk of the report was built on direct quotes, organised thematically, from people interviewed in the second stage of the research (Campbell \& Christie, 2013), but the report encompassed findings and analysis from both phases of the research. Overall, nine Department of Housing bureaucrats and 14 Aboriginal people participated in the project.

The seven main messages of the report were summarised as follows:

1. In Aboriginal communities good housing and its negotiated deployment are seen as crucial determinants of health, wellbeing, and local governance. Much community distress is attributed to poor housing and bad allocations.

2. Cultural authorities in remote communities and town camps play an often hidden but ongoing role in decision making about housing, which should be recognised and integrated into HRG processes.

3. The current policy of 'advice only' creates many problems, both at the community level and at the interface between government and community. Careful on-theground negotiations and decision making within HRGs would very seldom end in disagreement, so the advice-only policy is potentially harmful and unwarranted. 
4. From the Aboriginal perspective, decisions about housing are not separate from decisions about health, education, employment, community development or economic development. The work of HRGs should therefore be integrated into wider collaboration between senior (and other) community members, and all levels of government.

5. Miscommunication and lack of communication around new works, allocations and repairs, and lack of timely responses results in much distress and acrimony. The establishment of more immediate and effective communication and accountability processes (for example a 1800 phone number), would improve the engagement of community members and the effectiveness of HRGs.

6. Issues around housing cannot be solved by the Department of Housing alone. A 'whole-of-government' approach is necessary to match the 'whole-ofcommunity' approach.

7. Senior community members who work with governments on decision making around housing and other issues should be remunerated for their knowledge, authority and insights.

\section{Reflections on Aboriginal evaluation and its relation to 'theory'.}

As academics and researchers we are constantly confronted with 'theory', which can be both interesting and exciting. However, if we are not careful, it can distract us from our engagement with the real world. We may be tempted to use 'northern theory' (Connell, 2007) as a lens through which to make sense of what Aboriginal (and other marginalised) groups are trying to tell us. Such an approach commonly sees researchers using the received theory to pre-empt the possibility of Aboriginal people sharing with us anything new, or different, or challenging to our cherished assumptions. In this paper we are attempting to articulate quite specific Aboriginal contributions to our thinking about housing (and evaluation). In this section we draw attention to five insights provided by the Aboriginal participants in this research and try to link them to academic theory and practice which has helped us to clarify their messages, critique the received theory, and create something new. One of the interesting things to note here is that the Aboriginal people we interviewed were from Arnhem land and Alice Springs Town Camps, people who have very different histories, languages and housing contexts, yet the stories they tell have strong connections.

1. First, we note something holistic about the Aboriginal understanding of housing and governmentality. People manage houses, houses manage people. HRGs are there to help people manage houses, but evaluating the HRGs simply as technical mechanisms, employs a top-down model which pathologises (or condemns) the impoverished and overcrowded occupants of (what is now) public housing. Understanding HRGs solely or primarily as technical mechanisms assists in obscuring injustices that may be perpetuated and, importantly, may foreclose possible action towards a more systemic solution. Thus our Aboriginal participants remind us of the 'social justice' approaches, 
aimed at unearthing underlying causes for social problems and suggesting ways of going on together (see for example Weinberg, 2008). Even further from what the structural theorists avow, our Aboriginal participants remind us that we must work towards social justice by paying attention to our land, our environment and our place in the world.

... Children just grow up, because of the land, and the old people... they are born gifted, with a talent which only the wise people, and which only the land can provide. And when they are born on the land they are chosen to be certain leaders in the tribes. Straight after the Wet Season when we sit down by the beach and look at the sea around the small islands of the hunting grounds of the reefs where we hunt turtles and the certain signs in the skies tell the stories, of clouds sitting in the air after people have eaten .... Actually, it tells the story that we are the right people of that country. (Guyula, 2010, pp. 18-19)

2. We were struck by the contrast between the rather disciplinary approach of some of the bureaucrats ...

You have a responsibility to put back into your community. So I would hope that people would put their hands up, and want to be involved, and when we set up an HRG that they'd come along and have a presence, and be actively involved... (Territory Housing employee cited in Campbell \& Christie, 2013, p. 23)

.... with the patient storytelling on the part of the Aboriginal elders, gently involving us in what years ago, we called 'conscientisation' (Friere, 1972). Back then of course, our focus was on helping Aboriginal students and their communities achieve what we took to be an in-depth understanding of the world, and the perception and exposure of social and political contradictions. Now the elders use traditional agreement making methods to 'conscientise' us and the people who fund and act upon our research. We see their subtle good-humoured storytelling as requiring us to back off from our easy assumptions about the functionality of HRGs and see them more clearly in their historical socio-political contexts.

3. We had our 'focus area' list (which looked at the workings of the HRGs- their constitution, selection, induction etc.) which we used to frame our interviews and discussions to focus on the work at hand, however we maintained a non-prescriptive attitude toward how each discussion unfolded. In our interviews with Aboriginal HRG members each question seemed to lead to a story about people, place and housing, which only indirectly addressed the problem of HRG efficacy. More correctly, the Aboriginal participants could see a quite different problem, of which the HRGs were a manifestation, and seemed to do with finding ways to go on together in good faith working through these housing and related dilemmas such as health, education, and environment. So much of the discussion was not about housing or HRGs, but on ways in which people come together and address the problems and remain accountable to the solutions. There is no top-down solution.

Reminded once again of the America pragmatist philosopher John Dewey's book The Public and its Problems, we were being guided to see the poor state of Aboriginal 
housing, the fractious HRG meetings, the frazzled street-level bureaucrats, the disappointed and disempowered elders, all as effects rather than causes of the problems of not making agreement on ways to go on together. We were directed away from making judgements about the effectiveness of specific mechanisms, rules or provisions. Rules and regulations work differently in different places depending upon the good will and the problem of the moment. Overall we came to see the dislocation between residents of Aboriginal housing, and government bureaucrats delivering the housing as an effect of not working together in good faith rather than a problem with the HRGs per se (although improving the HRGs would certainly help). It wasn't a fundamental dislocation, there was good and bad on both sides of the divide, but our research findings led us towards reading the process from the (Aboriginal) view of conflict resolution, rather than from the (government) view of improving the workings of an ordered governmental structure. As a result, our report made no differentiation between Aboriginal and non-Aboriginal voices in the quotations which made up most of our evaluation report since everyone saw Aboriginal housing equally - although differently - as a difficult issue.

4. Everyone had good words to say about the hapless bureaucrats whose job it is to drive or fly to very remote Aboriginal communities, dealing with dirt roads, extreme heat, tiny planes, and violent storms as they set up meetings, find a quorum, keep focus, report back to government, bring often bad news of unpopular decisions, and explain government policy. These, we were told from people at all places within the system, are committed people doing the best of a very difficult job - the sort of working-in-good-faith which is so valued by the Aboriginal participants. What became clear to us, after triangulating and revisiting, was the extent to which the success of the Street Level Bureaucrat depended upon their moment by moment discretion in often difficult settings. They sometimes bent rules or ignored them, they had creative ways of becoming quorate, they did their best to keep the meetings focussed, and when they went off on a tangent they went to talk to people who might help (they knew, and had ongoing relations with many people in the community). This was also true of the HRG members, who, for example, worked hard to have the ideas of the traditional landowners included in the decision making even when they had been excluded from membership. Talking about the way that negotiations around housing in their communities can and do work, the Aboriginal people prosecuted a vision of negotiation reminiscent of the work of Lipsky (1980), who wrote of street level bureaucrats as the policy makers, because in a real sense the only "policy" that the public experiences is that which is mediated through their contact with street level bureaucrats. In this sense, "policy" is the cumulative effect of the individual decisions made by street level bureaucrats. It was clear that in the reflections of the Aboriginal participants, these street level workers on both sides of the divide were the true policy people, but there was more to it than that. They were not just clever bureaucrats, but decent people of good faith who, no matter how much they were positioned so by the system for which they worked, were not unconcerned, judging observers (Addelson, 1993). They were in the field, confronted by and having to deal with a range of issues, not all of which were related to housing. 
5. Finally, we set out, or were sent out, to conduct an evaluation of the system of HRGs. Within the wider research brief, our research questions were phrased, quite naturally, as technical questions. How big? How often? What training? Those technical questions were reworked, by the Aboriginal people we talked to, into ultimately moral questions. The stories - some funny, some sad, some outrageous - all seem to move the ostensibly technical question of housing and its administration towards an ethical question of working honourably together. This was done through a very natural but subtle narrative technique locating the actors in the broad socio-economic and political situation of remote Aboriginal people living on their own land with their own histories (Christie, 2013b).

\section{A surprising end}

So much of this project was disappointing. We had begun by taking a generative approach to our research; we didn't want simply to come up with a report, but to actually change practice. We have unashamedly come to see ourselves as activist researchers - we are participants in the world, not detached observers, and we want to make a difference. Our big question, and the one we continue to ask ourselves, is 'how do we do this responsibly?' How do we create the space and processes for ourselves and for others to do "work that is respectful of the creativity of others as they enact truth and take part in making the meaning of the world"? (Addelson, 1994, p. 8). In terms of enacting our process, we talked to as many people as we could. We asked them how we might be able to help. We transcribed the interviews and sent them back to be extended, shared or changed. We asked if there are people or groups we could talk to or work with to actually implement some of the proposed changes. We heard nothing. We sent out reminders, but received nothing back. We made the report and sent it out expecting to get some feedback - maybe from senior bureaucrats telling us we hadn't done what we were paid to do. Nothing.

Some months later, we were approached by government to undertake another, much larger project which involved (among other things) looking carefully at which different community-level advisory organisations could better work together or be amalgamated (what we had called the 'whole-of-government - whole-of-community' approach). We were asked to investigate the possibilities of making payments to senior community members who were spending increasing amounts of time doing indispensable facilitation work for government workers. We expressed surprise at what seemed to be a complete change around in policy around remuneration, and were told in passing, in a meeting with government, that this new thinking had came out of our housing report. Someone, somewhere, had been listening, thinking and reading, invisibly to us but clearly within the corridors of power.

We have spent much time reflecting on how the Aboriginal evaluation responses had somehow brought about this surprising change. Perhaps the ongoing effort in keeping the process public, or having Aboriginal voices prominently telling an alternative story 
about housing, generated an awareness that previously was absent. Either way, a critical revelation is that there are other ways to change policy than through the more traditional method involving membership within the 'policy development' system.

Understanding how this particular change might have come about is an important question, and given the circumstances of this change our attention is drawn to what Kathryn Pyne Addelson calls "double participation" (1994). As academic researchers with an interest in generative methodologies, we worked hard to be inclusive, providing the other participants in the project with numerous opportunities to contribute to the process, the findings, the report and further action. As it turned out, this did not seem to work in the way we imagined it would. We are prompted then, to think more deeply about the notion of, 'providing others with opportunities' to be involved. How are we positioned? How might this affect the work we do? And what might emerge as a result? As academic researchers whether we like it or not, we are agents of governance. As such, rightly or wrongly, we assume the right to know in our own terms. As professionals we have a lot of power to frame how things are understood, and what is to be included and excluded. We assumed at the outset that other participants would want to be involved in this knowledge making process; after all, they knew much more about what went on within HRGs than we did. However it turned out that it was our double participation that appeared to make the decisive difference, our ability to function both in the day to day world of bureaucrats and housing residents, where we learnt about HRGs and how they worked, but also our ability to turn this into another kind of story, one that operated in other contexts. It was this double participation that allowed the voices and perspectives of Aboriginal people to be heard and to make a difference.

It is hard not to feel that there is something a little bit wrong about this, because it was our professional power that ultimately appeared to make the difference. It is important to note that if this is the case, it was our professional power used responsibly. That is, we did not seek to create an authoritative account on our own terms. Our attempt at using a generative process privileged the views and methods of the people and the contexts we encountered in an iterative process, and it was this that allowed us to produce the report we did.

In the end, it appears that all those unanswered emails, (apparently) unchecked texts and the simple public 1-3-25 may have finally contributed to enough momentum, visibility and implicit agreement to precipitate a slight change in policy and a call for a new consultancy which entailed 'development' rather than just 'research'. As noted, this understanding relied on the validity and rigour of our process, bringing diverse stories together in a way that made sense and illuminated something about the HRGs and the processes that surround them that had hitherto been invisible. We still find it puzzling, upon reflecting on Aboriginal contributions to our evaluation, how hard it is to distinguish between what we had been told about good housing, and about good evaluation. This seems to lead towards new, more holistic thinking about evaluation. Aboriginal participants refused to be blamed for poor participation in HRGs and required everyone to view the technical problem of HRGs as the moral problem of working together across cultures productively and in good faith around the inseparable problems of community housing, health, education and environmental management in the here and now. 


\section{References}

Addelson, K.P. (1993) Knowers/Doers and their moral problems. In L. Alcoff \& E. Potter (Eds.), Feminist epistemologies. (pp. 265-301). New York, NY: Routledge.

Addelson, K.P. (1994) Moral Passages: Toward a Collectivist Moral Theory. New York, NY: Routledge.

Addelson, K. P. (2002) The Emergence of the Fetus. In C. Mui, \& J. Murphy (Eds.) Gender Struggles: Political Approaches to Contemporary Feminism. (pp.118136). Lanham: Rowman \& Littlefield.

Campbell, M., \& Christie, M. (2013). More than a Roof Overhead: consultations for better housing outcomes. Retrieved from http://www.cdu.edu.au/centres/yaci/ docs/MTROreport2.pdf

Christie, Michael. (2013a). Generative and 'Ground-Up' Research in Aboriginal Australia., Learning communities: International Journal of Learning in Social Contexts, (13), 3-13.

Christie, Michael. (2013b). Talking home and housing: The ethnographer brought back down to earth. Learning Communities: International Journal of Learning in Social Contexts, 12, 29-34.

Connell, R. (2007). Southern Theory: the Global Dynamics of knowledge in social science. Cambridge, UK: Polity Press.

Council of Australian Governments. (2008). National Partnership Agreement on Remote Indigenous Housing, Retrieved from http://www. federalfinancialrelations.gov.au/content/npa/housing/remote_indigenous_ housing/national_partnership.pdf

Dewey, J. (1927/1954). The Public and its Problems. Athens, Ohio: Swallow Press.

Freire, P. (1972). Pedagogy of the oppressed. Harmondsworth, Middlesex: Penguin.

Guyula, Yingiya. (2010). The Story comes along and the children are taught Learning Communities: International Journal of Learning in Social Contexts Australia (2), 18-22.

Lipsky, M. (1980). Street level bureaucracy: dilemmas of the individual in public services. New York: Russell Sage Foundation.

National Partnership Agreement on Remote Indigenous Housing (2008). National Indigenous Reform Agreement. Retrieved from http://www. federalfinancialrelations.gov.au/content/npa/housing/remote_indigenous_ housing/national_partnership.pdf

Weinberg, M. (2008). Structural Social Work: A Moral Compass for Ethics in Practice. Critical Social Work, (9), 1. 


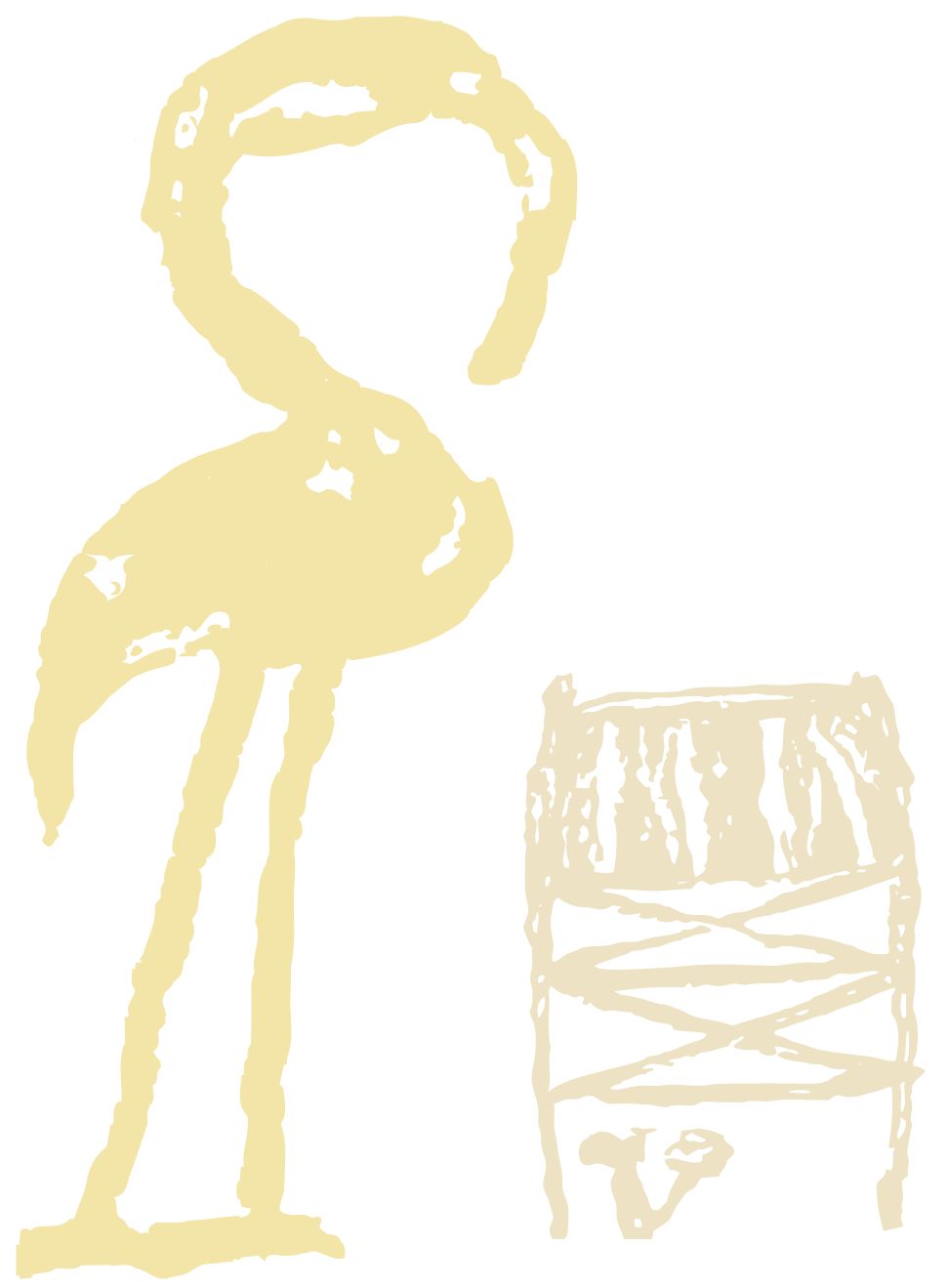

